\title{
VIVÊNCIAS RELIGIOSAS CRISTÃS INCLUSIVAS EM MARINGÁ E CURITIBA, PARANÁ, E AS SIGNIFICAÇÕES DAS SEXUALIDADES
}

\author{
Adriana Gelinski* \\ Marcio Jose Ornat**
}

\begin{abstract}
RESUMO
Esta reflexão tem como objetivo compreender como as diferentes vivências espaciais dos membros LGBT da Igreja Episcopal Anglicana de Curitiba (IEA) e da Igreja da Comunidade Metropolitana de Maringá (ICM) constituem as significações sobre suas sexualidades. Essas constituem-se enquanto uma possibilidade de vivências e práticas religiosas para pessoas LGBT. Foram realizadas 13 entrevistas seguindo roteiro semiestruturado. As entrevistas foram transcritas e sistematizadas a partir da análise de conteúdo do discurso, o que resultou em 987 evocações, tendo sido classificadas em espacialidades discursivas e categorias discursivas. Evidencia-se a presença do discurso religioso em todas as espacialidades cotidianas das pessoas entrevistadas e o paradoxo espacial de inclusão/exclusão.

Palavras-chave: Espaço. Sexualidades. Significado. Igreja. Diversidade.
\end{abstract}

* Mestra em Gestão do Território pela Universidade Estadual de Ponta Grossa - UEPG, PR. Graduada em Geografía pela UEPG, PR. Pesquisadora do GETE - Grupo de Estudos Territoriais.

** Pós-Doutor em Geografia e Sexualidades (Universitat Autònoma de Barcelona - 2016); Doutor em Geografia pelo Programa de Pós-Graduação em Geografia (Universidade Federal do Rio de Janeiro - 2011). É professor Adjunto B, no Departamento de Geociências, da Universidade Estadual de Ponta Grossa. Desde o ano de 2011 é co-coordenador do Grupo de Estudos Territoriais (GETE) e pesquisador do Grupo de Pesquisa Instrumentações Geotecnológicas - UNICENTRO 


\title{
VIVENCIAS RELIGIOSAS CRISTIANAS INCLUSIVAS EN MARINGÁ Y CURITIBA, PARANÁ, Y LAS SIGNIFICACIONES DE LAS SEXUALIDADES
}

\begin{abstract}
RESUMEN
La presente reflexión tiene como objetivo comprender cómo las diferentes vivencias espaciales de los miembros LGBT de la Iglesia Episcopal Anglicana de Curitiba (IEA) y de la Iglesia de la Comunidad Metropolitana de Maringá (ICM) constituyen las significaciones sobre sus sexualidades. Estas se constituyen como una posibilidad de vivencias y prácticas religiosas para las personas LGBT. Se realizaron 13 entrevistas siguiendo un itinerario semi-estructurado. Las entrevistas fueron transcritas y sistematizadas a partir del análisis de contenido del discurso, lo que resultó en 987 evocaciones, habiendo sido clasificadas en espacialidad discursivas y categorías discursivas. Se evidencia la presencia del discurso religioso en todas las espacialidades cotidianas de las personas entrevistadas, y la paradoja espacial de inclusión y exclusión.
\end{abstract}

Palabras clave: Espacio. Sexualidad. Significado. Iglesia. Diversidad.

\section{INCLUSIVE CHRISTIAN RELIGIOUS LIVING IN MARINGÁ AND CURI- TIBA, PARANÁ, AND THE MEANINGS OF SEXUALITIES}

\begin{abstract}
The present reflection aims to understand how the different spatial experiences of the LGBT members of the Episcopal Anglican Church of Curitiba (IEA) and the Metropolitan Community Church of Maringá (ICM) constitute the meanings about their sexualities. These constitute as a possibility of experiences and religious practices for LGBT people. 13 interviews were conducted following a semi-structured script. The interviews were transcribed and systematized from the content analysis of the speech, which resulted in 987 evocations, having been classified in discursive spatiality and discursive categories. It is evidenced the presence of religious discourse in all the daily spaces of the people interviewed, and the space paradox of inclusion and exclusion.
\end{abstract}

Keywords: Space. Sexuality. Meaning. Church. Diversity. 


\section{INTRODUÇÃO}

A presente reflexão tem como objetivo compreender como as diferentes vivências espaciais dos membros LGBT da Igreja Episcopal Anglicana de Curitiba (IEA) e da Igreja da Comunidade Metropolitana de Maringá (ICM) constituem as significações sobre suas sexualidades. Ambas diferenciam-se das igrejas constituídas por discursos fundamentalistas, pois suas práticas teológicas e interpretações dos textos bíblicos estão ancoradas em perspectivas histórico-críticas (Augustus Nicodemus LOPES, 2005). A interpretação fundamentalista dos textos bíblicos pressupõe que cada detalhe é divinamente inspirado, não há erros ou incoerências, bem como, tende a "absolutizar o sentido literal da Bíblia" (Uwe WEGNER, 1998, p. 12). Tais textos contêm a palavra de "Deus", "inspiradas de tal forma à mente humana que não são historicamente condicionadas, mas provêm, infalivelmente e de certa forma, extra-historicamente de Deus" (Augustus Nicodemus LOPES, 2005, p. 19). No entanto, ao compreender os textos bíblicos como fundamento da Teologia, faz-se necessário atentar que há uma reflexão humana acerca de tais textos e a respeito do divino. Isto se dá em uma perspectiva histórica "sendo presente o fundamento cristológico que a identifica e como esse fundamento foi compreendido nas diferentes fases de evolução do cristianismo" (Augustus Nicodemus LOPES, 2005, p. 20). Também, como apontado por Elisa Rodrigues e Elizangela Soares (2013, p. 52), "embora a Bíblia seja interpretada e entendida como a "Palavra de Deus", trata-se de uma fonte escrita por pessoas humanas, em linguagem humana e, portanto, com caráter simbólico, social e ético".

A existência da ICM-Maringá e da IEA-Curitiba é um desafio para a Teologia, pois estabelece a ela uma demanda de confronto com a História, sendo ela demandada a ler aquilo que é denominado enquanto "sinais do Reino de Deus", ou como o que é chamado por José Castillo (2016 [2013]) de "Reinado de Deus", como aquilo que foi ensinado por Jesus Cristo. Segundo esse autor, é isso que pode ser deduzido a partir da leitura dos evangelhos sinóticos, relacionados a Mateus, Marcos e Lucas. ${ }^{1}$ Portanto, a Teologia tem uma tarefa, não apenas para a compreensão do passado, mas para o nosso tempo.

1 Bíblia Sagrada. Tradução João Ferreira de Almeida, 2. edição. São Caetano do Sul: Grupo Scripturae, 2014. 
Evidencia-se o fortalecimento do movimento fundamentalista cristão de um lado, e de outro, o movimento contrário ao movimento fundamentalista, que acolhe e se aproxima das perspectivas teológicas inclusivas e contextuais (André MUSSKOPF, 2008; Marcelo NATIVIDADE e Leandro de OLIVEIRA, 2009; Karen ARMSTRONG, 2001). As igrejas ICM-Maringá e IEA-Curitiba são exemplos dessas igrejas, as quais não utilizam os textos bíblicos como fundamento único de fé e prática social. Para tanto, a ICM-Maringá e a IEA-Curitiba questionam e contextualizam as afirmações de textos bíblicos como "Com homem não te deitarás, como se fosse mulher; abominação é" visualizado em Levítico 18:22, ${ }^{2}$ em "Quando também um homem se deitar com outro homem, como com mulher, ambos fizeram abominação; certamente morrerão; o seu sangue será sobre eles". ${ }^{3}$ evidenciado em Levítico 20:13, ${ }^{4}$ ou em:

Por isso Deus os abandonou às paixões infames. Porque até as suas mulheres mudaram o uso natural, no contrário à natureza. E, semeIhantemente, também os homens, deixando o uso natural da mulher, se inflamaram em sua sensualidade uns para com os outros, homem com homem, cometendo torpeza e recebendo em si mesmos a recompensa que convinha de seu erro (ROMANOS 1:26-275).

Outro ponto em comum entre os membros LGBT da ICM-Maringá e dos membros gays ${ }^{6}$ da IEA-Curitiba está na vivência religiosa ao decorrer das vidas do grupo pesquisado. Todas as pessoas foram batizadas e cresceram em "berço religioso" (Adventista, Assembleia de Deus,

Bíblia Sagrada. Tradução João Ferreira de Almeida, 2. edição. São Caetano do Sul: Grupo Scripturae, 2014.

3 Na versão "Bíblia King James Atualizada" (1611 [2012]), o mesmo versículo trata que "O homem que se deitar com outro homem como se fosse uma mulher, ambos cometeram uma abominação, deverão morrer, e seu sangue cairá sobre eles" (Levítico 20:13). Se na tradução de João Ferreira de Almeida (Bíblia Sagrada, 2014) a morte aparece como algo casual, pois "certamente morrerão", em "Bíblia King James Atualizada" (1611 [2012]) a morte aparece como uma sentença.

4 Bíblia Sagrada. Tradução João Ferreira de Almeida, 2. edição. São Caetano do Sul: Grupo Scripturae, 2014.

5 Bíblia Sagrada. Tradução João Ferreira de Almeida, 2. edição. São Caetano do Sul: Grupo Scripturae, 2014 .

6 Importante destacar que na Igreja Episcopal Anglicana de Curitiba, de toda a população LGBT, apenas homens gays frequentam os cultos, ou participam da gestão da igreja. 
Batista, Brasil para Cristo, Presbiteriana, Universal do Reino de Deus e Católica).

Foi evidenciado pelas pessoas entrevistadas que as antigas comunidades religiosas são tidas formalmente como uma espacialidade confortável, de alívio frente às mazelas da vida. Todavia, de forma paradoxal, configuram-se enquanto espaços de opressão e exclusão para pessoas/grupos que não se enquadram naquilo que é tido pela denominação como "correto" e "natural". Ademais, os discursos religiosos presentes nas antigas comunidades religiosas compreendem o mundo a partir da noção binária e heterossexual mulher/feminina e homem/ masculino. As pessoas que não seguem essa linearidade são tidas como desviantes ou "doentes espirituais". Tais pensamentos estão ancorados em três pressupostos: 1) Deus existe, 2) Se revela através da Bíblia, pois a Bíblia é sua revelação, e 3) esse evangelho é divulgado aos quatro cantos da Terra por pessoas que são "Ungidas do Senhor". Tudo isso tem lastro no texto que é a revelação do "Todo-Poderoso".

Para tanto, este artigo compreende as experiências, as práticas e os discursos religiosos como agentes do funcionamento do mecanismo de gênero, regulando as práticas humanas e criando ficções de feminilidades e masculinidades como naturais (Judith BUTLER, 2003 [1990]). Evidencia-se o discurso religioso relacionado às sexualidades, reiterando a heteronormatividade, sendo justificada pelo discurso sexualizador do pecado, caso as pessoas não sigam a linearidade entre sexo, gênero e desejo (Judith BUTLER, 2003). Esses discursos estão relacionados às espacialidades e, por sua vez, estão conectados com as práticas espaciais. Assim, o discurso contribui para dar sentido e reiterar práticas espaciais, como afirma Mary Jane Spink (1999).

Nosso referencial metodológico esteve relacionado à análise de conteúdo do discurso proposto por Laurence Bardin (1977) para a análise das falas dos membros LGBT da ICM-Maringá e dos membros gays da IEA-Curitiba. Nesse sentido, foram realizadas 13 entrevistas seguindo roteiro semiestruturado com os membros LGBT da ICM-Maringá e da IEA-Curitiba. Oito entrevistas foram feitas com os membros LGBT da ICM-Maringá. Por sua vez, na IEA-Curitiba foram realizadas cinco entrevistas com os homens gays. 
No que se refere à análise de conteúdo do discurso, esse processo metodológico está relacionado ao desmembramento do texto - no caso, da fala resultante do processo de entrevista - em unidades denominadas de evocações, para em seguida processar o reagrupamento de acordo com essas mesmas categorias, ou como a partir de nosso olhar, segundo espacialidades discursivas.

Em um momento seguinte, esses mesmos trechos de entrevistas desmembrados foram organizados segundo "categorias discursivas" de recordações de fatos que se referiam às espacialidades ou tratavam das espacialidades. Todo este processo metodológico resultou em 987 evocações que foram classificadas em 'espacialidades discursivas' e 'categorias discursivas'.

Portanto, este artigo propõe-se compreender as diferentes vivências espaciais dos membros LGBT da ICM-Maringá e da IEA-Curitiba e como estes estão relacionados às significações de suas sexualidades.

\section{ESPAÇOS RELIGIOSOS, GÊNERO E SEXUALIDADES}

Como tratado por Doreen Massey, John Allen e Phillip Sarre (1999), o conceito de espaço tem sido um termo central na forma como podemos compreender a sociedade. De acordo com essas afirmações, o conceito de espaço tem se colocado como fundamental para a forma como compreendemos o mundo, e como podemos nos orientar através dele. Para esses autores, evidencia-se na produção das Ciências Sociais e das Humanidades aquilo que pode ser caracterizado enquanto a 'virada espacial'. Isso tem emergência da compreensão do espaço enquanto feito, ou seja, elaborado por intermédio de práticas que são materialmente incorporadas segundo a produção de um espaço vivido, ou como um dos resultados de uma versão de performances inter-relacionais. Da mesma forma, as identidades são co-constituídas por meio do fazer de tempos e espaços. O argumento dos autores é de que o espaço está permanentemente em processo de ser feito, ele é aberto. Todo esse movimento de manutenção e de contestação/transformação também é constituinte dos espaços religiosos. 
Entendido por Doreen Massey (2008, p. 191) como lugar, um evento, o espaço é para essa autora um conjunto de encontros "como a integração de espaço e tempo, como eventualidades espaço-temporal”. Assim, as espacialidades da igreja ICM-Maringá e IEA-Curitiba surgem por intermédio das vivências, das relações e das práticas, estando em constante movimento, sendo ao mesmo tempo material e imaterial. Portanto, os encontros de vivência espacial dos membros das ICM-Maringá e da IEA-Curitiba não são simples encontros espaço-temporais, mas se colocam como eventos.

Ademais, são cheios de significado e efeito, podendo ser negociados e renegociados constantemente. Tanto a IEA-Curitiba como a ICM-Maringá são locais institucionalizados de encontros, de práticas, de sociabilidades, os quais contribuem para a significação e ressignificação das concepções de mundo de seus membros. Logo, esse evento é feito por um conjunto de encontros entre as pessoas, e das pessoas com a ideia de que as vivências espaciais da/na ICM-Maringá e IEA-Curitiba possibilitam o contato com o divino/Deus.

O processo de investigação deste trabalho evidenciou que tanto a ICM-Maringá quanto a IEA-Curitiba são simultaneamente singulares e plurais. São singulares no seu início e na sua construção, sendo, portanto, espacialidades específicas e únicas para cada pessoa. Ao mesmo tempo são plurais, devido às relações e práticas sociais vivenciadas coletivamente, como nos momentos de celebração eucarística/culto e atividades em grupo vivenciadas pelas pessoas membros. Pensando assim, os espaços religiosos podem atuar como um articulador dos discursos, das fantasias e das corporeidades, bem como contribuir para dar forma ao conjunto de alianças e conquistas, o que Gillian Rose (1999) denomina de espaço performático.

Nessa perspectiva, a partir de nossa investigação, a ICM-Maringá e a IEA-Curitiba são, portanto, entendidas de maneira relacional, constituídas através da interação e das práticas entre as pessoas, mesmo a ICM-Maringá e IEA-Curitiba tendo especificidades de práticas litúrgicas e discursos. Em específico sobre a ICM-Maringá, autointitulada inclusiva desde o seu surgimento em 1968, compartilha de compreensões teológicas relacionadas a ser inclusiva, queer e gay. De outra forma, a IEA-Curitiba tem uma 
prática litúrgica de origem anglicana, mas também é caracterizada por sua flexibilidade de compreensão teológica. Na IEA-Curitiba existe a presença de gays na organização do espaço religioso, na secretaria, liderança da pastoral da diversidade e nos momentos de louvor. ${ }^{7}$

Ambas as igrejas interpretam os textos bíblicos a partir de um entendimento contextual e histórico-crítico, buscando compreender o contexto de cada texto bíblico. Assim, compreendem a sexualidade como parte integrante de cada pessoa, rompendo com a relação de sexualidade entendida como pecado. Realizam interpretações alternativas dos textos bíblicos, buscando romper com estigmas e discursos homofóbicos sobre a diversidade sexual.

Para tais articulações entre discursos, fantasias e corporeidades, Gillian Rose (1999) denomina enquanto performances relacionais, as quais contribuem para a formação de um espaço específico. Por exemplo, a ICM-Maringá e IEA-Curitiba, que possuem práticas e discursos teológicos específicos, como o discurso teológico feminista, queer e histórico-crítico. Por sua vez, igrejas com práticas e performances de outros tipos, com outros tipos de relação, produzem outras espacialidades. O espaço, portanto, não é algo fixo e sem aberturas, mas está em constante movimento de ser feito, é ativo e produzido de acordo com as performances situadas na relação entre o eu e o outro (Gillian ROSE, 1999). Dito de outra maneira, as espacialidades da ICM-Maringá e da IEA-Curitiba atuam como articuladoras, dando forma às alianças, às práticas, aos discursos e às fantasias.

Com base nas afirmações de Doreen Massey (2008) sobre espaço e identidade, essa relação é compreendida por meio de práticas, pois para a autora a identidade não é compreendida de forma essencializada, mas sim é relacional e constituída nas próprias relações sociais. Tal relação leva em consideração as vivências, a subjetividade e os discursos. Desse modo, é um erro pretender reivindicar que a identidade é imutável/ fixa, pois depende do que Doreen Massey (2008) denomina de política de inter-relação, onde há uma tríade entre identidade, relação e espa-

É importante salientar que a Catedral Anglicana de São Tiago, em Curitiba, surgiu em 1952, mas foi no ano de 2003 que passou a ser Catedral da Diocese Anglicana de Curitiba, da Igreja Episcopal Anglicana, como fora evidenciado no processo de investigação. 
cialidade, as quais estão relacionadas e são co-constitutivas. Logo, as relações sociais são constituídas e constituem o espaço. Os membros da ICM-Maringá e IEA-Curitiba vivenciam práticas religiosas e relações sociais nos espaços religiosos, sendo que tais relações e vivências contribuem para constituir, significar e ressignificar categorias identitárias como as sexualidades.

Ao refletirmos sobre a complexidade do espaço religioso inclusivo LGBT, podemos considerar o espaço constituído pelas inter-relações e interações dos discursos, fantasias e corporeidades, como afirma Gillian Rose (1999). Assim, compreendemos nosso fenômeno a partir dessa tríade, pois os membros LGBT sentem a necessidade de estar no espaço religioso expressando suas identidades de gênero/orientações sexuais, sem que sejam rejeitados ou apontados como "pecadores", uma vez que a sexualidade está inscrita na corporeidade deles.

As performances contribuem para a existência de um espaço específico, sendo que ao passo que as interações e relações mudam, há a produção de outros espaços (Judith BUTLER, 2008). Portanto, de acordo com Gillian Rose (1999), as espacialidades são praticadas enquanto a matriz de um jogo que é interativo e dinâmico, relacionado a formas e configurações que são produzidas segundo as performances situadas, e que dialogam com a heteronormatividade.

De acordo com Judith Butler (2003), a noção da heteronormatividade se dá de forma invisível até o momento que haja o rompimento das fronteiras. Isso acontece quando há a existência de pessoas fora da norma imposta. Desse modo, ser homem ou ser mulher está relacionado à norma heterossexual, em que um conjunto de ideias, valores e normas são construídos e reproduzidos por meio das vivências, crenças e linguagem. Logo, as pessoas que não seguem uma ordem ou a norma heterossexual sentem em seus corpos a interdição em alguns grupos e espaços, entre eles os espaços religiosos.

Cada espaço religioso pode ser compreendido como um espaço envolto por discursos que constituem a noção de mundo organizado por dois polos: normal (as pessoas que seguem os papéis e práticas de acordo com os textos bíblicos) e não normal ou "desviados": (as pessoas que não seguem os discursos e práticas, bem como, a norma heteros- 
sexual). O espaço religioso fundamentalista, por sua vez, é composto por normas binárias e heterossexuais, sendo assim entendido como um espaço heterossexual (Gill VALENTINE, 1993).

Segundo Pierre Bourdieu (1999), evidencia-se que a religião tem função da manutenção e conservação da ordem social como nós a conhecemos, e a partir da sua estrutura linguística, legitimar o poder dos dominadores e domesticar os dominados. De acordo com o dicionário Michaelis on-line, ${ }^{8}$ o adjetivo "funcional" é "Relativo à função ou ao exercício de uma função" ou "Relativo às funções vitais". Assim, podemos tratar de uma perspectiva funcional da religião, na medida em que ela é constituída por uma matriz heterossexual que produz inteligibilidade a corpos, gêneros e desejos. Compreendemos que essa matriz está relacionada de um lado à ideia de "contrato heterossexual" de Monique Wittig (1992) e, de outro, com aquilo que é denominado por Adrienne Rich (2010) de "heterossexualidade compulsória".

Indo além, para Pierre Bourdieu (1999), a estrutura interna da mensagem religiosa tem objetivos, funções sociologicamente definidas, orientada em favor dos grupos que a produzem e aos grupos que a consomem, justificando a posição de cada indivíduo no sistema social. Tais afirmações dialogam com a configuração do cristianismo no Brasil, quando visualiza-se o acirramento de posicionamentos político-religiosos conservadores no Congresso Nacional, relacionados aos trabalhos da Bancada Evangélica e Católica. Como visto em Dermi Azevedo (2004), ambas as bancadas organizam-se em aliança para votar juntas em projetos que estão relacionados a questões morais (Estatuto do Nascituro, casamento entre pessoas do mesmo sexo, adoção de crianças por casais homossexuais, manutenção de direitos LGBT, educação inclusiva etc.). Portanto, salvo no encaminhamento daquilo que é chamado por Ricardo Castro (2015) de Teologia do Genitivo, uma Teologia Setorial aberta ao diálogo horizontal, em Pierre Bourdieu (1999) a religião tem por objetivo a reprodução social dos sistemas de dominação.

Como visto por Vitor Barletta Machado (2013), existe uma proximidade dessa afirmação com a compreensão marxista da religião (Karl MARX, 2013 [1843]), entendendo-a como "ópio do povo". Assim,

8 http://michaelis.uol.com.br/ 
permanecendo com Pierre Bourdieu (1999), a função da religião é a do controle de uma instituição social, com fins de exercer o controle sobre a vida de seus fiéis. (Vide a história do processo sexualizador do pecado, já discutida por autores como Michel FOUCAULT, (1988 [1976]; 1984a-b), Jean-Phillipe CATONNÉ (2001) e Thomas LAQUEUR (2001))

Como tratado por Vitor Barletta Machado (2013) e evidenciado por Augustus Nicodemus Lopes (2005), diferentemente da rigidez religiosa impressa pela compreensão de Pierre Bourdieu (1999), há alterações significativas das compreensões teológicas que tensionam a manutenção das próprias estruturas religiosas. ${ }^{9}$ Contudo, mesmo que haja tensionamentos dentro da Teologia Cristã, abrindo caminho para o surgimento do novo, como visto na argumentação citada, é notório que a religião impõe uma estrutura de princípios que compõem nossas compreensões de mundo, impondo práticas e representações.

Tendo por base o conceito de "elite", incluindo tanto os chamados "donos do poder" (político, econômico e religioso), quanto a nova 'burguesia' brasileira, João Silvério Trevisan (2007) argumenta que as elites brasileiras, tendo visto serem detentoras de um conjunto de ideais de tradição patriótica e valores patriarcais, sempre estiveram na defensiva em relação à vivência homossexual, tornando-se permeáveis à homofobia, na medida em que buscavam zelar pelas normas morais. A religião - ou aquilo que é denominado por João Silvério Trevisan (2007) como a ação dos 'donos do poder religioso' - teria mais esta função, de apresentar a realidade como resultado de uma ação natural-sobrenatural do cosmos (Pierre BOURDIEU, 1999). ${ }^{10}$ Portanto, existem relações assimétricas de força entre o establishment teológico cristão e uma manifestação teológica cristã subversiva.

Cada espaço religioso está envolto por práticas e discursos sobre

9 Um exemplo seria a fundação da Pastoral da Diversidade, na Paróquia Bom Jesus dos Perdões, na cidade de Curitiba, Paraná. Tal pastoral, além de lutar em prol do fortalecimento dos direitos LGBT dentro de uma estrutura rígida, como a da Igreja Católica, tal pastoral é coordenada por uma mulher trans, a Sra. Maysa Regina Francener. Fonte: <http://www.franciscanos.org. $\mathrm{br} / \mathrm{p}=124613>$. Acesso em 5 de setembro de 2017.

10 Essa matriz de inteligibilidade produzida pela religião é elemento de discussão tanto de Pierre Bourdieu (1999) como de Peter Berger e Thomas Luckmann (1968), Peter Berger (1985), Karl Marx (2013 [1843]), Émile Durkheim (1978) e Max Weber (1930 [2013]). 
como se comportar, se vestir e se expressar. Esses elementos compõem a corporeidade das pessoas. Para tanto, esse corpo não é imóvel, é constituído pelas relações e negociações presentes em um espaço e tempo, como propõem Joseli Maria Silva e Márcio José Ornat (2016). A relação entre gênero, sexualidade e religião é um importante caminho para compreender o desenvolvimento das igrejas e as relações de poder que se estabelecem nas disputas espaciais em torno da conquista de fiéis (Marcelo NATIVIDADE, 2006). A vivência religiosa é permeada pela forma como as pessoas são interpretadas socialmente, nas relações de poder e nos discursos religiosos.

Ao pensar a construção do dispositivo da sexualidade e do mecanismo de gênero, Michel Foucault (1988 [1976]) ressalta que são processos que estão envoltos por relações de poder, bem como, estão em movimento e tensão. Dessa forma, Michel Foucault (1979) define o dispositivo da sexualidade como um conjunto de discursos (científicos, biológicos, morais, filosóficos e religiosos), passando por instituições até decisões regulamentares como as leis. Em suma:

...o dito e o não dito são os elementos do dispositivo, é a rede que se pode tecer entre estes elementos, que inventam, modificam, reajustam, segundo as circunstâncias do momento e do lugar, a ponto de se obter uma estratégia global, coerente, racional (Michel FOUCAULT, 2000, p. 244).

Judith Butler (2003), ao conceituar o mecanismo de gênero, ressalta que esse mecanismo também é um mecanismo de poder. Joan Scott (1989) compreende o gênero como uma forma de significar as relações de poder. O mecanismo de gênero regula e normatiza os corpos, sendo que esses corpos, por sua vez, aqueles que não seguem esse modelo regulatório, são passíveis de punição e vigilância para se adequar às regras estabelecidas (Judith BUTLER, 2003) nas mais variadas instituições e espaços, como a casa, escola e a igreja. Nesse sentido, Judith Butler (2003) afirma que o mecanismo de gênero reforça e naturaliza as noções de masculino e feminino. Segundo a autora, é a partir dos discursos e práticas constantemente repetidos que a noção de gênero é concebida. Reforça que o gênero não é o que somos em essência, mas é algo que foi produzido, reproduzido e naturalizado. 
Cada pessoa é composta por corpo, gênero, sexualidade e religiosidade, constituindo a relação entre esses elementos a identidade de cada pessoa. E mesmo que o funcionamento teológico se apresente como hegemônico, não há um destino único e fixo para os corpos (Judith BUTLER, 2003), mas sim estes são mutáveis, podendo-se subverter e rearticular a lógica normativa imposta pelos padrões sociais de sexo, gênero e desejo.

O espaço, as relações e os discursos estão conectados e compõem a vivência das pessoas, ao passo que determinados espaços podem ser acolhedores e outros excludentes. Além disso, os espaços, de acordo com Doreen Massey (2000), são constituídos pelas relações, compreendendo que o espaço é o lugar de encontro. É possível compreender o espaço como lugar, o qual se dá por uma constelação de histórias e relações que se encontram e se refazem constantemente, como evidenciado no processo de levantamento de campo na ICM-Maringá e IEA-Curitiba. Evidenciamos que todas as pessoas entrevistadas foram socializadas em igrejas evangélicas ou católicas, as quais reiteram compreensões teológicas, discursos e práticas religiosas que alimentam a compreensão das sexualidades dissidentes como pecado.

Há uma defesa da heterossexualidade compulsória, ou seja, uma desqualificação de sexualidades dissidentes da heterossexualidade como norma. Assim, ao se afirmar a heterossexualidade como única e legítima forma de exercício do desejo (Judith BUTLER, 2003), legitima-se o pensamento linear de sexo, gênero, desejo e práticas como algo natural, 'correto', esperado por Deus. No entanto, tal pensamento confere inteligibilidade, importância e materialidade ao "sexo" biológico, tomando diferenças de gênero e subordinações culturalmente constituídas como se fossem "naturais", como afirma Judith Butler (2003).

São várias as formas e intensidades de reiteração da heterossexualidade compulsória, "variando desde o total silêncio acerca da diversidade sexual e de gênero até a produção de estereótipos que operam por uma franca estigmatização de pessoas LGBT" (Marcelo NATIVIDADE e Leandro de OLIVEIRA, 2009, p. 13). Ademais, as perspectivas teológicas hegemônicas articulam-se com políticas que justificam seus posicionamentos homofóbicos na cosmologia, passagens bíblicas e práticas 
cristãs preconceituosas. Indo além, tais discursos permeiam todas as espacialidades cotidianas reiterando assim a norma heterossexual.

\section{AS EXPERIÊNCIAS ESPACIAIS E RELIGIOSAS DOS MEMBROS DA ICM-MARINGÁ E DA IEA-CURITIBA E A COMPREENSÃO SOBRE SUAS SEXUALIDADES}

Mesmo que os membros LGBT da Igreja Episcopal Anglicana em Curitiba e da Igreja da Comunidade Metropolitana em Maringá tenham inúmeras vivências espaciais, seus discursos evidenciam que suas amplas possibilidades espaciais são também constituídas por princípios religiosos. Os espaços vivenciados pelos membros LGBT da ICM-Maringá e IEA-Curitiba estão conectados com discursos, práticas e experiências, os quais são entendidos e sentidos de maneiras distintas, contribuindo assim para as significações e para a constituição das identidades individuais e do grupo.

Ao analisar os paradoxos vivenciados pelos membros LGBT da ICM-Maringá e da IEA-Curitiba, evidenciou-se que os mesmos mesclam suas experiências espaciais, isto é, práticas religiosas interseccionadas com as categoriais identitárias. Por meio dos discursos dos membros LGBT, tanto da ICM-Maringá quanto da IEA-Curitiba, é possível compreender suas significações em relação às sexualidades.

Faz-se necessário ressaltar que o grupo pesquisado da ICM-Maringá é composto por quatro gays, um bissexual, duas travestis e uma muIher trans. Já o grupo pesquisado da IEA-Curitiba é composto por cinco membros gays. Para tanto, evidencia-se que as categorias discursivas da ICM-Maringá e da IEA-Curitiba conectam-se com as espacialidades, visto que todas as categorias discursivas estão em relação e se co-penetram.

Para tanto, esta discussão é fruto da análise de conteúdo de 13 entrevistas, oito delas realizadas com os membros LGBT da ICM-Maringá e cinco entrevistas com membros da IEA-Curitiba. Dessa forma, o Gráfico 1, a seguir, é resultado das evocações evidenciadas pelos membros LGBT da ICM-Maringá e dos homens gays da IEA-Curitiba, Paraná, as quais colaboraram para a construção deste gráfico e, por conseguinte, para a sua análise. 
GRÁFICO 1 - ESPACIALIDADES DOS MEMBROS LGBT DA ICM-MARINGÁ E DA IEA-CURITIBA - PR

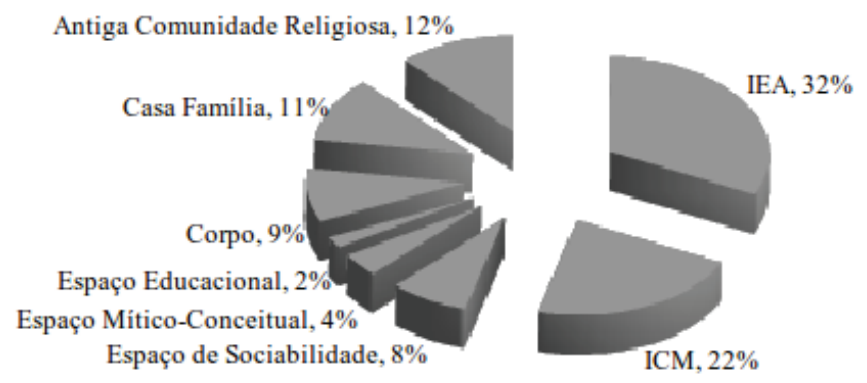

FONTE: Entrevistas realizadas com membros LGBT da ICM-Maringá, Paraná e da IEA-Curitiba entre os dias 4 de janeiro de 2016 a 28 de julho de 2016. Organizadora: Adriana GELINSKI, 2017.

A intensidade de evocações remete a determinado espaço, bem como os diferentes espaços estão relacionados com as experiências espaciais e religiosas. Assim, evidencia-se não somente os espaços religiosos, mas os mais variados espaços cotidianos dos membros entrevistados. Nesse sentido, nosso objetivo foi analisar como cada espacialidade contribui para as significações individuais e coletivas em relação às sexualidades. Evidenciaram-se, portanto, oito espacialidades (ICM-Maringá, IEA-Curitiba, antiga comunidade religiosa, casa da família, corpo, espaço educacional, espaço mítico-conceitual e espaço de sociabilidade). Para tanto, tendo visto o escopo da presente reflexão, estaremos tratando em específico das três espacialidades mais evocadas, sendo elas: a atual comunidade religiosa (ICM-Maringá, IEA-Curitiba), antiga comunidade religiosa e a casa da família.

As igrejas ICM-Maringá e IEA-Curitiba configuram-se com algumas características diferentes, as quais se referem à localização e estrutura, o surgimento de cada comunidade religiosa e a organização dos momentos litúrgicos. No entanto, as categorias discursivas evidenciadas a partir de ambos os grupos são semelhantes. Para os membros LGBT da ICM-Maringá, identificaram-se as categorias discursivas 'acolhimento' com $20 \%$, 'vida religiosa' com 19\%, 'interpretação bíblica' com 16\%, ‘direcionamento' em $14 \%$ e 'relações sociais’ com $12 \%$. Por sua vez, os membros 
gays da IEA-Curitiba possuem as mesmas categorias discursivas, mas com intensidades diferentes. Posto que 'vida religiosa' corresponde a $29 \%$, 'acolhimento' a 19\%, 'interpretação bíblica' com 22\%, 'relações sociais' com $12 \%$, 'pecado' em 10\% e 'direcionamento' com $10 \%$.

Constata-se, por conseguinte, que as categorias discursivas 'acoIhimento' e 'vida religiosa' são as primeiras para ambos os grupos. No entanto, a categoria discursiva 'acolhimento' é indicada com 20\% pelos membros LGBT da ICM-Maringá e 19\% pelos membros gays da IEA-Curitiba. Já a categoria discursiva 'vida religiosa' é apontada com $26 \%$ pelos membros IEA-Curitiba e 29\% pelos membros LGBT da ICM-Maringá. Revela-se que ambas as espacialidades religiosas (ICM-Maringá e IEA-Curitiba) têm grande importância para as pessoas entrevistadas, pois é por intermédio delas que há o acolhimento, despertando o sentimento de conforto e respeito. Como evidenciado nas falas de Veja e Taurus:11

Lá fora a gente se sente como um pássaro preso na gaiola. Na ICM a gente sente que não tem nada que tem que prender a gente, que a gente é livre, Deus ama a gente como a gente é. Então a gente basta seguir o caminho Dele e o que os outros pensa, e o que as outras igrejas pensa não vale a pena, vale a pena você acreditar assim e seguir como é. Deus ama eu como eu sou então tá bom demais, tá ótimo (Entrevista realizada com Veja na ICM-Maringá, Maringá, em 27/01/2016.)

É um lugar que encontrei pessoas sem preconceito sabe, sobretudo, são pessoas humanistas, na Igreja Anglicana, fui acolhido como filho de Deus independentemente de minha trajetória, fui percebido como pessoa. Pra início de conversa, ninguém em nenhum momento perguntou o que eu era, não houve nenhum questionamento sobre minha orientação. Porque isto não importa aos olhos de Deus (Entrevista realizada com Taurus, IEA-Curitiba, 8/01/2016.)

As espacialidades religiosas atuais são locais que despertam o sentimento de pertença ao grupo, uma coletividade (Guy ROCHER, 1971). É no espaço ICM-Maringá ou no espaço IEA-Curitiba que seus respectivos

1 Buscando proteger nossas fontes, substituímos os nomes das pessoas entrevistadas por nomes de estrelas. 
membros têm a liberdade de vivenciar as práticas e os discursos religiosos, conciliando com as suas sexualidades. Tais espaços constituem-se como locais de "consagramento, pertença e solidariedade entre os membros" (Guy ROCHER, 1971, p. 169). Por sua vez, as categoriais discursivas evidenciadas pelos membros LGBT da ICM-Maringá e dos homens gays da IEA-Curitiba relacionadas à espacialidade 'antiga comunidade religiosa' são semelhantes em sua maioria. Para os membros LGBT da ICM-Maringá a categoria discursiva 'vida religiosa' constitui-se com 35\%, precedida da categoria discursiva 'preconceito' com 13\% e 'homofobia' com $10 \%$. Seguida ainda pelas categorias discursivas 'interpretação da Bíblia' e 'relações sociais' com $8 \%$ e a categoria 'acolhimento' com $3 \%$.

Para os membros gays da IEA-Curitiba, a categoria discursiva 'vida religiosa' é evidenciada com $20 \%$. Já a categoria 'preconceito' constitui-se com $5 \%$, com a categoria 'relações sociais'. A categoria discursiva 'interpretação da Bíblia' é evidenciada com 23\% e a categoria 'acolhimento' com 3\%.

Dessa forma, a categoria discursiva 'Vida religiosa' foi evidenciada com $35 \%$ pelos membros da ICM-Maringá e $20 \%$ pelos membros gays da IEA-Curitiba, dados esses relacionados à espacialidade 'Antiga Comunidade Religiosa'. Segundo o discurso de Procyon, a antiga comunidade religiosa fazia parte de sua rotina, assim como os discursos e as práticas religiosas, constituindo-se em espaço de sociabilidade e contato com algo divino. Evidencia-se, desse modo, a importância desse espaço nas experiências sociais e religiosas. Ademais, esse espaço está conectado com o processo de descoberta e revelação da sexualidade, como pode ser visto na fala a seguir:

Nossa era muito legal, eu gostava bastante porque antes assim tinha grupo de jovens à gente saía, a gente conversava muito, a gente ensaiava e jogava também. Tipo era muito legal aquele convívio que tinha entre os jovens, né. Tipo um ia dormir na casa do outro e tipo era tudo jovens assim sabe muito legal (Entrevista realizada com Procyon, Maringá, em 6/11/2015.)

A espacialidade 'antiga comunidade religiosa' dos membros LGBT da ICM-Maringá e a IEA-Curitiba era constituída pelo sentimento posi- 
tivo relacionado à vivência da fé. No entanto, os discursos religiosos acabavam reiterando a heterossexualidade como norma, bem como o pecado relacionado diretamente às sexualidades.

Diante do exposto, comprova-se o preconceito presente na espacialidade 'antiga comunidade religiosa'. Logo, a categoria discursiva 'preconceito' é evocada pelos membros LGBT da ICM-Maringá totalizando $13 \%$ e pelos membros gays da IEA-Curitiba com $5 \%$. Evidencia-se que a espacialidade discursiva 'antiga comunidade religiosa' constitui-se como um espaço de preconceito em relação às sexualidades. Pensamento fundamentado em 'verdades divinas', pois a sexualidade que não corresponde à heterossexualidade é vista como uma doença demoníaca, a qual precisa passar pelo processo de 'cura' e 'libertação', como enuncia a fala que segue:

Assim porque quando assim você é menininho, você menininho sem os trejeitos gays, eles até aceitam mais, mas naquela época eu era muito afeminado. Ai eu era muito gay na verdade, era uma bichona, era uma bichona mesmo, passava lápis e tudo. Então eles se assustavam sabe, eles falavam que eu tava com o demônio, orava por mim, ponhava a mão na minha cabeça expulsando satanás "sai satanás!!!" essa coisa toda aí. Então, eles acham que isso é errado sabe, que não que Deus não aceita a gente, que Deus odeia a gente e pronto. Eles querem curar a gente, faziam eu ler e ler a bíblia para ser e essas coisa para curar, sendo que a gente não tem nada. Então, era difícil eles aceitarem, mas assim eu ia mesmo assim, mas eu não podia participar de nada, eu não podia cantar, eu não podia dançar, não podia nada nada nada. Só tava lá só. (Entrevista realizada com Rigel, ICM-Maringá, em 21/01/2016.)

Revela-se nessas situações o sentimento de aversão à não linearidade entre sexo, prática sexual e desejo. Marcelo Natividade e Leandro de Oliveira (2009) ressaltam que várias são as motivações para as reações de repúdio e menosprezo para com uma categoria identitária da pessoa. A fala já citada evidencia nos discursos religiosos o repúdio à sexualidade dissidente, caracterizando assim as formas de vestir, os gestos, a corporalidade, as práticas e os desejos como algo pecaminoso.

A terceira espacialidade discursiva a ser analisada é a 'casa da família', a qual apresenta $11 \%$ do total de evocações dos membros LGBT 
da ICM-Maringá e IEA-Curitiba, Paraná. A ‘casa da família’ constitui-se como uma espacialidade de grande importância para compreender as concepções religiosas e consequentemente as visões de mundo, a noção de 'certo e errado', 'bom e mau', bem como as concepções relacionadas às sexualidades. Assim sendo, essa espacialidade relaciona-se diretamente com discursos religiosos, bem como com a espacialidade 'antiga comunidade religiosa', visto que todas as pessoas entrevistadas provêm de famílias religiosas.

Para tanto, as categoriais discursivas evidenciadas pelos membros LGBT da ICM-Maringá e dos homens gays da IEA-Curitiba relacionadas à espacialidade 'casa da família' são semelhantes em sua maioria. As categorias discursivas 'ausência de aceitação da família', 'aceitação da família', 'experiência' e 'preconceito' são apontadas por ambos os grupos entrevistados. Assim, a categoria discursiva relacionada à 'ausência de aceitação da família', da espacialidade discursiva 'casa da família', nos revela a relação com a intenção de preservar os princípios religiosos da família. Estes, por sua vez, fundamentados nos discursos e práticas vivenciados pela família na 'antiga comunidade religiosa', as quais são os elementos que constituem a espacialidade 'casa da família'.

Destaca-se a dificuldade de compreender a homossexualidade por parte da família, pois a noção de sexualidade da família está exclusivamente fundamentada nos discursos religiosos e nos textos bíblicos. Isso contribui para a resistência de compreensão e aceitação da família em relação às sexualidades, bem como para a negação e para a tentativa de aniquilar sua própria sexualidade. Estes elementos são evidenciado nas falas que seguem:

E a minha família, meu pai meu pai foi um homem muito ruim sabe. Até hoje ele é ruim sabe, ele é aquele muito rústico sistemático, na verdade ele nunca foi pai, foi pai por ser assim na verdade. Porque quem criou a gente foi a minha vó e assim ele foi ele é muito bruto, ele assim homem é homem, mulher é mulher e pronto. Não tem esse negócio de homossexual, de gay isso é coisa do satanás e pronto pra ele. Deus o livre travesti ou trans não tem isso pra ele. E eu tinha muito muito medo dele, muito medo dele sabe, Deus me livre se ele soubesse de alguma coisa. E eu fui crescendo, aí tive uma experiência com menino tal e foi incrível. E aí pronto, mas demorou pra mim 
aceitar, pra mim entender o que é gay, o que é homossexual, o que é uma drag. Até, no entanto, eu achava que isso era errado, que era a pior coisa do mundo ser gay sabe, que eu não queria sabe, eu me perguntava muito por que Deus permitiu ser assim que eu não queria. (Entrevista realizada com Rigel, ICM-Maringá, em 21/01/2016.)

Pra mim foi meio complicado tipo me assumir né automaticamente direto pra mim que até hoje eu tenho esse próprio preconceito comigo mesmo. Mas quando me assumi como gay pra minha família, minha mãe não aceita até hoje, minha mãe tipo reluta pra aceitar, mas hoje graça a... demorou assim 10 anos pra ela poder chegar e tá aceitando que nem tá hoje, né, poder ir na casa dela conversar com ela, tipo brincar com ela, dar risada com ela mas ainda luta um pouco contra isso um pouco preconceito ainda existe na família. (Entrevista realizada com Canopus, ICM-Maringá, em 20/01/2016.)

A fala de Canopus vai ao encontro do que André Musskopf (2008) problematiza quando aborda sobre as formas normativas de vestimentas, demonstração de afeto e relacionamentos, apreendidos e reiterados pelo discurso religioso. Para a pessoa 'ser bem-vista' pela comunidade religiosa e pela sua família, é necessário seguir um rol de normas. No momento em que as pessoas deixam de cumprir um dos requisitos 'listados', tornam-se assim desviantes da "Palavra de Deus".

Em outros termos, a sexualidade é um dos 'requisitos', e as pessoas que fogem das regras estabelecidas são entendidas como doentes, filhas/os das trevas, um pecador/pecadora constante. As pessoas vivenciam a negação e o conflito entre 'sair do armário' e o discurso sexualizador do pecado, pois, como afirma Marcelo Natividade e Leandro de Oliveira (2009), qualquer prática homossexual é interditada pelo discurso religioso fundamentalista.

Desse modo, evidenciamos que para ambos os grupos, tanto os membros da ICM-Maringá como para os membros da IEA-Curitiba, Paraná, a 'casa da família' é evocada como uma espacialidade majoritariamente desconfortável, pois a ausência de aceitação se fez ou se faz presente entre os familiares perante suas sexualidades. Isso, por sua vez, fez-se presente no desenvolvimento da sexualidade dessas pessoas, contribuindo assim para a sua negação, para a ausência de 
autoaceitação devido aos conflitos, aos medos e culpas internalizadas pelos discursos e práticas preconceituosas da família, esses permeados de concepções normativas e fundamentalistas.

\section{CONSIDERAÇÕES FINAIS}

O presente artigo evidenciou como as diferentes vivências espaciais dos membros LGBT da Igreja da Comunidade Metropolitana de Maringá e os membros da Igreja Episcopal Anglicana de Curitiba constituem as significações de suas sexualidades. Nesse sentido, a espacialidade da igreja pode ser compreendida como uma possibilidade de vivência cotidiana de pessoas que comungam de determinada forma de compreender e significar o mundo. Nesse contexto, a relação entre sexualidades e religiosidade é um importante caminho para compreender as concepções e formas de interpretar o mundo segundo as mais variadas categorias identitárias.

Para tanto, várias são as espacialidades presentes no cotidiano do grupo pesquisado, as quais são constituídas por discursos e práticas, que estão diretamente ligados à constituição das significações e ressignificações das pessoas. Indo além, estão relacionados às categorias identitárias do grupo pesquisado, evidenciando-se o gênero, as sexualidades e a religiosidade com grande relevância na vida dessas pessoas.

As experiências espaciais dos membros LGBT da ICM-Maringá e dos membros gays da IEA de Curitiba são significadas a partir das relações, das trocas e das vivências. Para tanto, evidencia-se que mesmo diante de inúmeras vivências nas três espacialidades (Atual Comunidade Religiosa, Antiga Comunidade Religiosa e Casa da Família) evidenciadas nesta discussão, a religiosidade faz-se presente, contribuindo assim para as visões de mundo. Entre as experiências mais marcantes apontadas pelos membros dessas igrejas está o momento de autoidentificação como LGBT e consequentemente a exclusão da vivência religiosa em suas antigas comunidades religiosas. Por conseguinte, há o conflito e o preconceito vivenciado na espacialidade 'casa da família', bem como a tentativa de aniquilar a sexualidade para se enquadrar nos discursos normativos.

Por meio da vivência religiosa nessas igrejas, há um rompimento das noções hegemônicas relacionadas à sexualidade. Indo além, por in- 
termédio das perspectivas teológicas, dos discursos e práticas religiosas de ambas as igrejas, há uma ressignificação na compreensão religiosa, por conseguinte, em relação às identidades, conciliando assim a vida religiosa e a sexualidade.

Nesse sentido, o grupo pesquisado, ao retornar para a vivência religiosa através da ICM-Maringá ou IEA-Curitiba, "reconcilia-se com Deus", harmonizando-se assim com sua vivência, com sua prática religiosa e com sua sexualidade. Portanto, evidencia-se a potencialidade dos discursos como fundamentais na constituição de identidades. No caso desta reflexão, o discurso religioso foi imprescindível para as experiências do grupo pesquisado, este atuando de modo central em suas decisões e concepções.

\section{REFERÊNCIAS}

ARMSTRONG, Karen. Em nome de Deus: O Fundamentalismo no Judaísmo, no Cristianismo e no Islamismo. São Paulo: Companhia das Letras, 2001.

AZEVEDO, Dermi. A Igreja Católica e seu papel político no Brasil. Estudos Avançados, v. 18, n. 52, p. 109-120, 2004.

BARDIN, Laurence. Análise de Conteúdo. Lisboa: Edições 70, 1977.

BERGER, Peter. O Dossel Sagrado: Elementos para uma Teoria Sociológica da Religião. São Paulo: Edições Paulinas, 1985.

BERGER, Peter; LUCKMANN, Thomas. La construcción social de la realidad. Buenos Aires: Amorrortu Editores, 1968.

BOURDIEU, Pierre. A Economia das Trocas Simbólicas. São Paulo: Perspectiva, 1999.

BUTLER, Judith. Cuerpos que Importan: sobre los limites materiales y discursivos del 'sexo'. Buenos Aires: Paidós, 2008.

BUTLER, Judith. Problemas de Gênero: feminismo e subversão da identidade. Rio de Janeiro: Civilização Brasileira, 2003.

CASTILLO, José María. O Reinado de Deus. Teologia Popular II. São Paulo: Edições Loyola, 2016 [2013].

CASTRO, Ricardo Gonçalves. Introdução à Teologia. Batatais: Claretiano, 2015.

CATONNÉ, Jean-Phillipe. A sexualidade, ontem e hoje. $2^{\mathrm{a}}$ edição. São Paulo: Cortez, 2001. DURKHEIM, Émile. As regras do método sociológico. São Paulo: Nacional, 1978. FOUCAULT, Michael. Em defesa da sociedade. São Paulo: Martins Fontes, 2000. FOUCAULT, Michael. História da Sexualidade I: a vontade de saber. Rio de Janeiro: Graal, 1988 [1976]. 
FOUCAULT, Michael. História da Sexualidade II: O uso dos Prazeres. Rio de Janeiro: Graal, $1984 a$.

FOUCAULT, Michael. História da Sexualidade III: O cuidado de si. Rio de Janeiro: Graal, 1984 b.

FOUCAULT, Michael. Microfísica do poder. Rio de Janeiro: Graal, 1979.

GELINSKI, Adriana. As Vivências Espaciais dos Membros LGBT da Igreja da Comunidade Metropolitana em Maringá e da Igreja Episcopal Anglicana em Curitiba e a Constituição das Significações de suas Sexualidades, 186 p. Dissertação (Programa de Pós-Graduação em Geografia - Mestrado em Gestão do Território) - Universidade Estadual de Ponta Grossa, Ponta Grossa, 2017.

LAQUEUR, Thomas. Inventando o Sexo: Corpo e Gênero dos Gregos a Freud. Rio de Janeiro: Relume Dumará, 2001.

LOPES, Augustus Nicodemus. O Dilema do Método Histórico-Crítico na Interpretação Bíblica. Fides Reformata X, n. 1, p. 115-138, 2005.

MACHADO, Vitor Barletta. Sociologia da Religião. Batatais: Claretiano, 2013.

MARX, Karl. Crítica da Filosofia do Direito de Hegel. São Paulo: Boitempo, 2013 [1843]. MASSEY, Doreen. Pelo Espaço: uma nova política da espaço. Rio de Janeiro: Bertrand Brasil, 2008.

MASSEY, Doreen. Um Sentido Global do Lugar. In: ARANTES, Antonio. Espaço da Diferença. Campinas: Papirus, 2000, p. 176-185.

MASSEY, Doreen; ALLEN, John; SARRE, Phillip. Human Geography Today. Cambridge: Polity Press, 1999.

MUSSKOPF, André Sidnei. Via(da)gens teológicas: itinerários para uma teologia queer no Brasil. São Leopoldo: EST/PPG, 2008.

NATIVIDADE, Marcelo Tavares. Homossexualidade, gênero e cura em perspectivas pastorais evangélicas. Revista Brasileira de Ciências Sociais, v. 21, n. 61, p. 115-132, 2006.

NATIVIDADE, Marcelo Tavares; OLIVEIRA, Leandro. "Nós Acolhemos os Homossexuais": Homofobia pastoral e Regulação da Sexualidade. Tomo, n. 14, p. 203-227, 2009.

$\mathrm{RICH}$, Adrienne. Compulsory Heterosexuality and Lesbian Existence. Revista Bagoas, n. 5, p. 17-44, 2010. (Tradução: Carlos Guilherme do Valle.)

ROCHER, Guy. Sociologia Geral. Lisboa: Editorial Presença, 1971.

RODRIGUES, Elisa; SOARES, Elizangela Aparecida. Introdução Geral à Bíblia e História de Israel. Batatais: Claretiano, 2013.

ROSE, Gillian. Performing Space. In: MASSEY, Doreen; ALLEN, John; SARRE, Philip. Human Geography Today. Cambridge: Polity Press, 1999, p. 247-259.

SCOTT, Joan Wallach. Gênero: uma categoria útil de análise histórica. Educação e Realidade, v. 20, n. 2, p. 71-99, 1989. 
SILVA, Joseli Maria; ORNAT, Marcio Jose. Corpo como espaço: Um desafio à imaginação geográfica. In: PIRES, Cláudia Luísa Zeferino; HEIDRICH, Álvaro Luiz; COSTA, Benhur Pinós da. Plurilocalidade dos Sujeitos. Representações e Ações no Território. Porto Alegre: Compasso Lugar-Cultura, 2016, p. 56-75.

SPINK, Mary Jane. Práticas Discursivas e Produção de Sentidos no Cotidiano. São Paulo: Cortez, 1999.

TREVISAN, João Silvério. Devassos no Paraíso: A homossexualidade no Brasil, da Colônia à Atualidade. Rio de Janeiro: Editora Record, 2007.

VALENTINE, Gill. (Hetero)sexing space: lesbian perceptions and experiences of everyday space. Environment and Planning D: society and space. v. 11, n. 4, p. 395-413, 1993. WEBER, Max. A Ética Protestante e o Espírito do Capitalismo. São Paulo: Martin Claret, 2013 [1930].

WEGNER, Uwe. Exegese do Novo Testamento. São Paulo: Editora Paulus, 1998.

WITTIG, Monique. El pensamiento heterosexual y otros ensayos. (Tradução: Javier Sáez e Paco Vidarte.) Beacon Press, Boston: Editorial EGALES, S.L., 1992.

Submetido em: 08-09-2017

Aceito em: 7-11-2017 